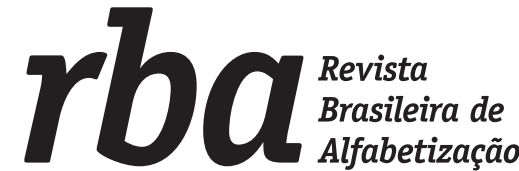

\section{POR UMA INFÂNCIA DA ESCRITA E DA LEITURA}

\author{
FOR A CHILDHOOD OF WRITING AND READING
}

\author{
Marcos Ribeiro de Melo \\ Universidade Federal de Sergipe (UFS) \\ marcos_demelo@hotmail.com \\ Michele de Freitas Faria de Vasconcelos \\ Universidade Federal de Sergipe (UFS) \\ michelevasconcelos@hotmail.com
Roselusia Teresa de Morais Oliveira Universidade Federal de Sergipe roselusiamorais@gmail.com

\section{Resumo}

Em diálogo com as artes literária e cinematográfica, este artigo aposta na infância da leitura e da escrita como "germe de vida" para a invenção de si e de mundo. A infância, não como uma etapa de um ciclo de vida, mas como "condição de experiência", como (des)limite da/na linguagem que, com sua força, desestabiliza práticas sociais, inclusive práticas escolares de escrita e leitura. Assim, tratamos da produção de um corpo leitor-escritor como experiência primordial que abrange uma cognição encarnada e um tempo de ressonâncias que não é o tempo cronológico dos relógios, do capital, e do desenvolvimento. Vivemos um tempo acelerado e, quando refletimos sobre as práticas de escrita e leitura escolares, tal aceleração, vinculada à necessidade de produtividade, dispersa a atenção sobre como se escreve e como se lê. Diante disto, nos perguntamos: o que pode a escola no que diz respeito à constituição desse corpo leitor-escritor? Apostamos que ela pode muito, pois esta mesma escola é um dos poucos lugares em que, mesmo atravessado pela disciplinarização dos corpos e aceleração da vida, seja possível uma certa suspensão do tempo e do espaço mercadológicos.

Palavras-chave: Leitura. Escrita. Infância. Corpo. Escola.

\begin{abstract}
In dialogue with the literary and cinematic arts, this article focuses on the childhood of reading and writing as a "germ of life" for the invention of the self and the world. Childhood, not as a stage in a life cycle, but as a "condition of experience", like a(n) (un)limited language, that with its strength, destabilizes social practices, including school reading and writing practices. Thus, we treat the production of a reader-writer body as a primary experience that encompasses an incarnated cognition and a time of resonances that is not the chronological time of the clocks, of capital, and of development. We live an accelerated time and, when we think about school writing and reading practices, such acceleration, linked to the need for productivity, disperses attention on how to write and read. Before this, we ask ourselves: what can the school do about the constitution of this reader-writer body? We bet it can do a lot because this same school is one of the few places, where even having the discipline of bodies and the acceleration of life, it's possible a certain suspension of time and marketing space.
\end{abstract}

Keywords: Reading. Writing. Childhood. Body. School 


\section{Por uma infância da escrita e da leitura}

Chegando em casa, não comecei a ler. Fingia que não o tinha, só para depois ter o susto de o ter. Horas depois abri-o, li algumas linhas maravilhosas, fechei-o de novo, fui passear pela casa, adiei ainda mais indo comer pão por alguns instantes. Criava as mais falsas dificuldades para aquela coisa clandestina que era a felicidade. A felicidade sempre iria ser clandestina para mim (LISPECTOR, 1971/2016, p. 396)

E o menino vai mudando de posição várias vezes, o corpo todo se remexe, se encolhe, se espicha, dando mil voltas no mesmo lugar. E os olhos? Ah, esses ficam vidrados, fixados naquela trama, movendo-se levemente de um lado para o outro, o suficiente para dar conta das palavras responsáveis pelo reboliço interno que acontece, como quem vive mesmo o enredo lá de dentro [...] (MILANEZ, 2019, p. 81)

Por entre palavras, histórias e personagens das crônicas de Clarice Lispector e Fernanda Milanez, iniciamos este escrito, tateando uma aproximação entre pesquisa, leitura e literatura; entre ciência, infância e a arte de ler e de escrever; entre esta arte e a escola. Ao ler Clarice e Fernanda, somos tomadas/o de emoção e emoções movimentam e inventam mundos (DIDI-HUBERMAN, 2016). Todavia, não nos referimos aqui a uma "emoção psicológica", a uma interioridade do indivíduo, mas a uma "emoção vital" que compõe aquilo que Rolnik (2016) chama de "saber-do-corpo", uma espécie de germe de mundo que nos habita; afectos e perceptos ${ }^{1}$ que nos compõem, produzindo estranhamento, desconhecimento e instabilidade. Trata-se de uma "experiência primordial, pois é sinal de alarme que nos indica que a vida nos levou a um estado desconhecido" (ROLNIK, 2016, p. 12).

Se inauguramos esse texto falando de emoção é porque, com Virgínia Kastrup (2008a, p. 104), apostamos na reconciliação da cognição com o concreto, ou seja, "numa cognição corporificada, encarnada, distinta da cognição entendida como processo mental. É tributária da ação, sendo resultante de experiências que não se inscrevem mentalmente, mas no corpo". Partindo dessa aposta na corporificação do conhecimento, Kastrup (2008b) pesquisa o acoplamento da criança com o livro, farejando que este acoplamento (se pensarmos na relação criança e televisão, criança e computador) instaura uma deriva subjetiva nesses tempos em que o livro se tornou um objeto obsoleto e sua leitura uma prática em desuso, pois demanda um tempo desacelerado, um demorar-se, um ritmo diferente do que a hiperconexão desses (nossos) tempos exige. A pesquisa de Virgínia se instaura em meio a oficinas literárias, envolvendo um(a) professor(a) que trabalha com um grupo de crianças, em formato de rodas de leitura em que o objetivo principal é a fruição do texto literário e o maior desafio é o de ensinar a gostar de ler. Por meio de suas observações, ela indica que "ler e escrever envolvem todo o corpo, e não só uma suposta mente separada" (KASTRUP, 2008b, p. 248). Ler e escrever abarcam a necessidade de construir um corpo de leitor(a), um trabalho de longo prazo, um processo de aprendizagem, em que a repetição funcionaria como modo de corporificar o conhecimento, o que é diferente de pensar em repetir para criar automatismos, condutas mecânicas. "A repetição que está envolvida na arte-aprendizagem é como a [...] de um ator que ensaia até incorporar o espírito do personagem, até cavar uma profunda intimidade com ele, até encarná-lo, corporificá-lo e com isso espantar a mediação da representação" (KASTRUP, 2008a, p. 107).

\footnotetext{
1 Fundamentado a partir dos estudos em Deleuze e Guattari (1992), rede de afectos e perceptos, é um conceito compreendido, neste trabalho, como uma possibilidade de encontro existente entre o leitor, o livro e o outro. Por meio das artes, a exemplo da literatura e/ou cinema, é possível ser afetado e transformado. Para Rolnik (2016, p. 10), esta rede de afectos e perceptos é ativada pela experiência das "forças que agitam o mundo enquanto corpo vivo e que produzem efeitos em nosso corpo em sua condição de vivente. Tais efeitos consistem em outra maneira de ver e de sentir aquilo que acontece a cada momento - às quais Gilles Deleuze e Félix Guattari deram o nome, respectivamente, de 'percepto' (diferente de percepção pois é irrepresentável) e 'afecto' (diferente de afeto ou sentimento, que são emoções psicológicas, pois aqui trata-se de uma emoção vital que tem a ver com afectar, no sentido de tocar, contaminar, perturbar)".
} 
Retomando: desejamos falar da produção de um corpo leitor e escritor como uma experiência primordial que abrange essa cognição encarnada e um tempo de ressonâncias que não é o tempo cronológico dos relógios do capital e do desenvolvimento (irmão do progresso) humano; envolve o escavar de um espaço-tempo-corpo para o pensamento, a linguagem, a sensibilidade e a ação, para que as palavras

[...] algumas palavras, antes que se desgastem ou se fossilizem para nós, antes de permanecerem capturadas, também elas pelas normas do saber e pelas disciplinas do pensar, antes que nos convertam, ou as convertamos em parte de uma doutrina ou de uma metodologia, antes que nos subordinem, ou as subordinemos a esse dispositivo de controle do pensamento que chamamos de "investigação", ainda [possam] conter um gesto de rebeldia, um não, e ainda [possam] ser perguntas, aberturas, inícios, janelas abertas, modos de continuar vivos, de prosseguir, caminhos de vida, possibilidades do que não se sabe, talvez (LARROSA, 2014b, p. 75).

Neste artigo apostamos na infância da leitura e da escrita como "germe de vida", num continuarmos a ler e escrever não para descrever um mundo dado, mas para invenção de si e do mundo. Assim, não falamos da infância dos compêndios pedagógicos e/ou psicológicos, presa a um movimento sucedido em etapas próprias a um ciclo vital, mas a infância como "condição de experiência", numa temporalidade intensiva e não numerável, a infância como (des)limite da/na linguagem (KOHAN, 2007; AGAMBEN, 2005). Como Manoel de Barros afirma em uma de suas inutilidades poéticas, "as coisas que não têm nome são mais pronunciadas por crianças" (BARROS, 2016, p. 16). Balbuciando o mundo e inventando palavras, a infância faz tremer nossas certezas sobre quem somos, o que sabemos, como lemos o mundo.

Deste modo, sentimos a força da infância em sua capacidade desestabilizadora das práticas sociais, inclusive as práticas de escrita e leitura, pois "dizer que aquele que nasce tem, como ponto de partida, o impossível significa, então, que o nascimento constitui a possibilidade de tudo o que escapa ao possível" (LARROSA, 1998, p. 194), ou dito de outra forma,

[...] se a criança é primeira em relação ao adulto não é por uma questão cronológica ou etária, mas, antes, por sua potência criadora, à qual outras forças em jogo não podem senão reagir tardiamente. Um mundo sem crianças é apenas um mundo, pois perde toda a possibilidade de multiplicar as experiências e as formas de vida (ALVIM; MAÇÃO, 2018, p. 71).

Ainda que não desconheçamos as diferenças analíticas entre as categorias "infância" e "criança", como afirmamos em outra oportunidade², transitamos numa direção onde a infância não é rascunho da vida adulta, mas um "situar-se intensivo; um sair do 'seu' lugar e situar-se em outros lugares, desconhecidos, inusitados, inesperados" (KOHAN, 2007, p. 94-95). Pensando sobre esta força da infância, compreendemos com Abramowicz (2018, p. 25), que se as crianças estão

2 Como afirmamos em Vasconcelos, Prates e Melo (2019, p. 32-33), "as diferenças entre as categorias analíticas de infância e criança foram inicialmente desenvolvidas no campo da história por Philippe Ariès (1981) ao afirmar que, somente a partir da Modernidade, foi possível forjar um sentimento de infância, correspondente '[...] à consciência da particularidade infantil, essa particularidade que distingue essencialmente a criança do adulto, mesmo jovem' (ARIÈS, 1981, p. 99). Sentimento que está presente na história do Ocidente, elaborado em concomitância com mudanças de composição da família, das ideias de maternidade, paternidade e escolarização. A invenção da infância possibilitou o surgimento de uma série de tecnologias de poder com o objetivo de gerenciar a vida dos indivíduos e populações. Nesse sentido, o dispositivo de infantilidade incita a produção de saberes sobre os corpos infantis, corpos de crianças. Tal dispositivo regula relações de poder e práticas institucionais em seu nome, sob a alcunha de garantia de direitos sociais, com implicações sobre sua 'saúde, alimentação, condições de existência, necessidades, interesses, desejos, identidade' (CORAZZA, 2004, p. 22). Por outro lado, não se deve compreender, como afirma Qvortrup (2011), que a criança seja um sujeito a-histórico. Em culturas e sociedades não-ocidentais, 'a ideia de infância pode não existir, ou ser formulada de outros modos. O que é ser criança, ou quando acaba a infância, pode ser pensado de maneira muito diversa em diferentes contextos socioculturais' (COHN, 2005, p. 22). Portanto, a criança, segundo Kramer e Motta (2010), é aquela 'pessoa de pouca idade', produtora e produzida pela cultura, que se constitui a partir de sua classe social, etnia, gênero, diferenças físicas, psicológicas e culturais”. 
"à mercê dos adultos e das forças que as querem alfabetizá-las rapidamente, das forças que as querem iniciá-las precocemente à lógica do capital, da linguagem hegemônica, do poder, das hierarquias de cor e raça, da heteronormatividade. Talvez o que as crianças tenham de mais potente seja a infância".

Nossa aposta vai na contramão da direção de inserir as crianças nos mapas linguísticos dos adultos, como presos políticos (DELEUZE, 1992b), estamos aqui pensando o encontro com uma leitura feita experiência ${ }^{3}$, incorporação e encarnação. Leitura que se faz abertura e atenção ao mundo que as passa, que as tomba e que as transforma (LARROSA, 2014a; 2018). As experiências das personagens trazidas por Lispector e Milanez no início do texto nos põem a pensar sobre as práticas de escrita e leitura escolares. Seriam elas capazes de provocar moções, emoções, de (de)formar e de trans-formar? Seriam elas capazes de produzir experimentações, derivas subjetivas? Práticas de escrita e leitura escolarizadas, da maneira como têm funcionado, produzem formas de ação ou fôrmas de ação? Seriam essas experiências de escrita e leitura infantilantes ${ }^{4}$ ?

Esses questionamentos demarcam um campo de reflexões possíveis para repensar a educação e as práticas de leitura e escrita em cenários escolares e não escolares. Os fragmentos da literatura de Clarice Lispector, em Felicidade Clandestina, de Fernanda Milanez, em Livros e panos, articulados posteriormente no texto com cenas do cinema francês dirigido por Sylvie Verheyde (2008), no filme Stella, expressam livros, infâncias e leitores/as que leem com fruição. Essas narrativas potencializam um repensar constante acerca de estratégias educativas que favoreçam a formação de leitores e escritores e, consequentemente, sejam capazes de seduzir e reinventar os usos e modos de ler e escrever. As práticas de leitura das personagens nas páginas literárias e em tela são traduzidas por uma riqueza de detalhes que envolvem o corpo do/a leitor/a, ao oferecer a possibilidade de constituir um amplo despertar dos sentidos em meio ao pleno encontro com os seus objetos de leituras, situados em códigos sociais próprios.

\section{0 contratempo da aprendizagem escolar}

Vivemos um tempo acelerado. Tempo de alta conectividade, tempo primo-irmão dos relógios das fábricas e das escolas, não mais encerrado em sistemas fechados, porém um tempo ultrarrápido de controle ao ar livre, onde nunca se termina nada e cuja sensação produzida é sempre endividamento (DELEUZE, 1992a). Esse cenário de hiperaceleração e virtualização crescentes atinge em cheio a educação e a escola em seus domínios práticos e teóricos, na medida em que insistem em lidar com a cognição e a aprendizagem como regidas por leis e princípios invariantes, apartados desse tempo, negando suas capacidades inventivas, seus movimentos, complexidades e multiplicidades (GADELHA, 2013).

\footnotetext{
3 Inspiradas/o pelos estudos e pensamentos de Jorge Larrosa sobre a relação entre experiência e educação, insistimos no uso do termo, mesmo sabendo que o filósofo espanhol optou pelo uso da palavra exercício em trabalhos recentes (LARROSA, 2017; 2018). Como ele enfatiza em seu abecedário: "A experiência é uma relação com o mundo na qual algo 'nos passa' e isso que nos passa, nos forma ou nos transforma. Mas, introduzindo aqui a palavra exercício, tenho introduzido uma mudança na ênfase, pois o acento não está tanto na transformação do sujeito, mas na atenção ao mundo. Daí que o exercício seja uma ginástica da atenção, mas também é uma condição da experiência e da experiência no sentido de que algo 'nos passe'. Hoje a experiência é uma palavra capturada pelo mercado, o shopping vende experiências, mas a palavra exercício não está tão capturada, é uma palavra bem escolar" (LARROSA, 2017, depoimento).

4 Neologismo criado por Kohan (2007) para evitar o sentido pejorativo do termo "infantilizar". Entendemos o infantilar e outras variações (meninar, crianceirar etc.), como possibilidades de suplantar a ideia de falta a tudo que remete ao infantil veiculada e naturalizada por teorias psicológicas e pedagógicas. Ao contrário, nossa mirada é de que, ao se infantilar, se acessa a uma temporalidade intempestiva de criação de mundo e de si.
} 
Quando refletimos sobre as práticas de escrita e leitura escolares, tal aceleração, vinculada à necessidade de produtividade, dispersa a atenção sobre como se escreve e como se lê, "uma vez que tais práticas servem apenas para comunicar e registrar, sendo que pouco Ihes acontece (CAMPESATO, RODRIGUES, e SCHULER, 2018, p. 303, grifos nossos). Perguntam as/o pesquisadoras/o:

\begin{abstract}
O que quer uma escola em que as crianças realizam dez exercícios de escrita por turno; em que leem e respondem perguntas como, por exemplo, "quem é o autor do texto ou qual o título do livro"? O que quer uma escola que utiliza Clarice Lispector apenas para ensinar tempo verbal? O que quer uma escola que opera com uma literatura que infantiliza e que reduz as fábulas ao "tu deves"? O que quer uma escola pública que passa um século escrevendo sobre Deus, Pátria, Família e Higiene? (CAMPESATO: RODRIGUES; SCHULER, 2018, p. 305).
\end{abstract}

No estilo de vida contemporâneo, caracterizado por uma hiperconexão às múltiplas redes e telas, imagens-textos saturam diuturnamente nossa sensibilidade e diminuem as possibilidades de um processamento consciente, ao passo que exigem respostas ágeis e eficazes às suas demandas (SIBILIA, 2012). O usuário midiático, quando a saturação chega ao nível de esgotamento, costuma estar entediado, disperso e desatento, mas geralmente está disponível a passar à próxima página do seu aplicativo de redes sociais, ao próximo perfil, sempre disposto a dar, rapidamente, sua "curtida", visto que o que o mantém conectado "nessa vivência não é o sentido do que observa, e sim a própria aceleração" (SIBILIA, 2012, p. 90). Um desafio se estabelece quando as subjetividades midiatizadas estão numa sala de aula:

[...] ao ler, estudar ou escrever como propõe o dispositivo escolar, por exemplo, experimenta-se um tempo cumulativo, linear, ascendente: cada momento requer uma etapa anterior que the dê sentido e coerência, como um avanço gradativo que se enquadra na lógica racional do progresso. Os meios audiovisuais e interativos, ao contrário, solicitam e incitam outras disposições corporais e subjetivas, bem distintas daquelas que são postas em prática pela leitura e a escrita (SIBILIA, 2012, p. 90).

Corroborando com estas análises, Kastrup (2008b, p. 246) admite que ler, principalmente os textos literários, demanda uma temporalidade diferente daquela que marca nossas experiências atuais. Sua hipótese é a de que "o regime de tempo da contemporaneidade constitui o principal obstáculo à prática da leitura", pois a disposição cognitiva exigida pelo livro, traduz-se numa trama que exige do corpo-leitor cavar uma temporalidade onde seja possível ler, reler e voltar a ler. "A possibilidade de releitura, parcial ou integral de um texto, caracteriza o texto em livro e é um de seus protocolos. O vaivém da leitura distingue bastante o livro de outros dispositivos" (KASTRUP, 2008b, p. 251).

Assim, mesmo entendendo que a ordem escolar contemporânea, produzida pelas políticas neoliberais, tem como meta a fabricação de subjetividades empreendedoras e a transformação da escola e da aprendizagem em mercadorias e bens de consumo (BIESTA, 2017; LAVAL, 2019), compreendemos ser esta mesma escola um dos poucos, ou talvez o único lugar que, mesmo atravessado pela aceleração da vida, seja possível uma certa suspensão do tempo e do espaço mercadológicos. Tempo tornado livre, liberado e não produtivo para profanar o saber instituído (MASSCHELEIN; SIMONS, 2013), além disso, neste contexto, educa-se a atenção, num "tipo de trabalho e de olhar para o mundo que não está disponível em outros espaços" (DUSSEL, 2017, p. 93). 
Onde ainda se lê uma poesia de Manoel de Barros, onde se escreve um conto com Machado de Assis, onde se retira livros da biblioteca, onde se lê em voz alta para um grupo? Com certeza não é no shopping, com a televisão ou no Big Brother. Isso, também, porque há uma forte dimensão política nas escritas das crianças na escola, uma vez que cada escrito fala de uma coletividade, de uma aula, de um estudo (CAMPESATO; RODRIGUES; SCHULER, 2018, p. 305).

A escrita e a leitura, como experiências de formação, são atividades que têm a ver com a constituição de um corpo leitor-escritor, o que se relaciona não só com o que ele sabe, mas com a possibilidade de perspectivar seu olhar e produzir subjetivações:

[...] trata-se de pensar a leitura [e a escrita] como algo que nos forma (ou nos de-forma e nos trans-forma), como algo que nos constitui ou nos põe em questão naquilo que somos. A leitura, portanto, não é um passatempo, um mecanismo de evasão do mundo real e do eu real. E não se reduz, tampouco, a um meio de conseguir conhecimento (LARROSA, 2007, 129-130).

Nossa questão prossegue: mas o que pode a escola no que diz respeito à constituição desse corpo leitor-escritor?

\section{Stella caiu na rede}

Como apontado no início deste trabalho, as experiências com a escrita e a leitura instalam uma rede de afectos que, na escola, se estabelece entre os livros, as professoras e as crianças. O contato produzido pela leitura em voz alta, pela escrita em grupo ou mesmo o próprio suporte material do texto (diagramação, ilustrações, letras, etc.) estabelece um plano de afectos que "envolve um movimento de saída de si, uma linha de fuga, que não faz virar as costas para as dificuldades, mas indica uma saída permitindo que se escape da paralisia que muitas vezes é gerada pela dificuldade" (KASTRUP, 2008b, p. 258).

Para pensar sobre esta rede de afectos e a experiência como formação a partir de imagens fílmicas ${ }^{5}$, recorremos ao filme Stella (Verheyde, 2008) pelas lentes de um exercício conceitual-metodológico da etnocartografia de tela (VASCONCELOS; MELO; SOUZA NETO, 2018). Pelo olhar falante da menina francesa somos guiados pela garota em encontros com a escola, os colegas de classe, seus professores e as tarefas que nunca consegue entender. "Eu não tenho muito contato com os outros. Não olho para eles e eles também não me olham", ouve-se em off a voz de Stella. $\mathrm{Na}$ tela, em movimento de close-up, assistimos ao encontro com aquela que será sua melhor amiga na escola: Gladys. Sentadas, lado a lado, aguardam a chegada do metrô. O olhar de Stella demonstra desconforto. Olha para cima, para os lados e finalmente para baixo, sem nunca encarar a garota que está ao seu lado. De um encontro ao acaso, de uma amizade em nascimento, gera-se uma força motriz de vida e de novos possíveis. Abrem-se palavras, perguntas, inícios, janelas abertas, caminhos de vida, modos de continuar vivas, larvárias, infantes, Stella e Gladys (LARROSA, 2017, p. 75).

5 Nesses tempos de pulverização excessiva de imagens, em que a tomada de poder sobre as subjetividades tem se dado por um acoplamento com políticas imagéticas que veiculam e reiteram imagens clichês (Deleuze, 1992b), temos ensaiado modos de resistência por entre imagens. Assim, para pensar infância, além da articulação com literatura, temos nos interessado por um cinema que possibilite afiar o pensamento com imagens menos como representação do mundo e mais como afecções, intensidades, rupturas nos modos amansados de ver e perceber (Wunder, 2016), dando passagem para novas políticas imagéticas e subjetivas. 
Na sala, novamente ouvimos a voz-pensamento de Stella: "Na classe, não entendo nada que perguntam. Eu não presto atenção, só finjo. Chego em casa e esqueço da escola. Amanhã eu vejo isso. Esquecer eu consigo fácil”. Entretanto, a força do encontro de Stella com Gladys produz centelhas que ampliam seu mundo. Na sequência de imagens, após estarem juntas numa reunião familiar na casa de sua nova amiga, onde Stella se depara com um debate sobre Kafka em pleno jantar, acompanhamos a compra do seu primeiro livro. O enquadramento traz, inicialmente, o ponto de vista da menina. As imagens tremem e, em primeiro plano, vemos mesas com livros amontoados. Ao fundo da cena, a atendente da livraria. Stella transita, visível e novamente desconfortável, entre estantes. Aquele, assim como a escola, parecia não ser seu mundo. Pega um livro e, cabisbaixa, realiza o pagamento. Ao atravessar a porta do estabelecimento em direção à rua, sai em disparada. Como Clarice em Felicidade Clandestina (1971/2016), Stella corre com vida, pela vida, da vida, para uma vida; como se fugisse de algo, em escape, como se atravessasse e fosse atravessada por outro mundo, pela produção de mundos, pela experiência de si que se inauguraria pelo "mover-se a ler".

Escrever e [ler] é como submergir num abismo em que acreditamos ter descoberto
objetos maravilhosos. Quando voltamos à superfície, só trazemos pedras comuns e
pedaços de vidro e algo assim como a inquietude nova no olhar. O escrito [e o lido]
não é senão um traço visível e sempre decepcionante de uma aventura que, enfim,
se revelou impossível. Nossos olhos apreenderam uma nova insatisfação e não se
acostumam mais à falta de brilho e de mistério daquilo que se nos oferece à luz do
dia. E algo no nosso peito nos diz que, na profundidade, ainda resplandece, imutável
e desconhecido, o tesouro (LARROSA, 2007, p. 156).

Os olhos de Stella aprenderam novas satisfações e passaram a enxergar o brilho de um tesouro: a leitura. As mudanças são evidentes até para sua mãe, que mal sabia o ano escolar em que a menina se encontrava. Sentada no chão da cozinha, Stella lê. Em close-up, a câmera filma o rosto de sua mãe que a convida para sair:

Mãe: - Vamos passear, estou de folga.

Stella: - Não estou a fim.

O olhar da mãe é de desconfiança e certo espanto.

Mãe: - Não está a fim? Não está a fim de um presentinho?

Stella: - Não. (desviando o olhar do livro por alguns instantes)

Mãe: - Você está doente?

Stella (voltando novamente os olhos para o livro): - Não.

Mãe: - Tá bem.

Stella (surrando e olhando novamente para mãe): - Quero terminar meu livro.

Mãe: - É para a escola?

Stella: - Não.

Mãe: - Que livro é?

Stella: - Balzac.

Mãe (olhando diretamente para escola enquanto mastiga um pão): - Você está lendo por prazer? Stella: - Sim.

Mãe: - Tá bom. Você está mudando, minha filha. Está mudando.

Agora Stella está em seu quarto e lê em voz alta. Vestida num suéter azul celestial, fixa seu olhar sobre o livro "Uma barragem contra o pacífico" de Marguerite Duras. A câmera centralizada filma a garota em plano fechado. Na tela são só Stella e o livro. 
Stella (lendo em voz alta): "Um dia, um carro irá parar em frente do bangalô. Um homem e uma mulher descerão para pedir uma informação ou uma ajuda qualquer a Joseph ou a ela. Ela não entende muito bem que tipo de informação eles poderiam pedir. Ali só havia uma estrada que ia de Ram até a cidade, passando por Kam".

A leitura cessa momentaneamente e a menina levanta o rosto. Os olhos perambulam inquietos no espaço, como que acompanhando pensamentos e sensações que aquele texto havia produzido. Uma emoção toma o seu corpo e ela retorna ao texto.

Stella (lendo em voz alta): "Ninguém podia errar o caminho. Mesmo assim, era impossível prever tudo e Suzanne esperava".

Novamente a leitura em voz alta é interrompida. Ouvimos os pensamentos de Stella: "um dia um homem vai parar, vai parar, talvez. Por que não? Pode ser que ele goste dela e a convide para ir até a cidade". Em sequência, as imagens mostram as lágrimas da menina e uma breve pausa em silêncio. As personagens da história agora habitam em Stella, alimentando sua vida e sua vontade de viver, num constante diálogo com ela. Em off ouvimos sua voz: "Ela fala comigo. Ela fala para mim. Ela fala no meu lugar. Não consigo parar de ler".

\section{Leitura e escrita: por entre políticas de cognição}

Diferentes modos de ensinar e aprender a ler e escrever compõem políticas de cognição também diferentes. Como assinala Kastrup (2008b), de um lado, há o modelo da representação, instaurando e reificando a ideia de preexistência de um sujeito cognoscente e de um mundo dado que se dá a conhecer; de sujeito e mundo-objeto como polos separados, dicotômicos. De outro, parte-se da ideia de que o mundo não é dado, mas efeito de práticas cognitivas. Aproximando-se conhecimento e criação, entende-se que a ação de conhecer coengendra sujeito e objeto, o si e o mundo. Assim, o mundo,

[...] o meio não instrui, não transmite informações. Não há determinismo, pois o próprio meio só existe enquanto for configurado pelo vivo. Não há meio a priori ou absoluto. Não se pode, portanto, falar em conhecer algo previamente existente. O que eu aprendo só surge com o meu aprender (KASTRUP, 2008b, p. 108).

Dessa forma, podemos afirmar que a cognição representacional e a inventiva são dois modos de estar no mundo, de estabelecer relações consigo, com a atividade de conhecer, inclusive, com práticas de leitura e escrita. Em nossas práticas cotidianas, como professoras/o universitárias/o, por entre ensino, pesquisa e extensão, nosso esforço tem sido o de perscrutar aprendizagens inventivas, recusando a crença em um mundo dado ao qual devemos conhecer para melhor nos adaptar, o qual apenas representamos, um mundo que coloca os problemas que devemos solucionar. Tal recusa comporia uma atitude, um esforço reiterado de encarnar uma nova política cognitiva afeita à invenção de problemas, à invenção de si e do mundo (KASTRUP, 2008b).

A partir dessa política cognitiva, conhecer é criar, produzir realidades e não representar um mundo já dado (KASTRUP, 2008b). Não há como conhecer previamente um mundo dado, pois o que se conhece é fruto do encontro entre o si e o mundo, a aprendizagem estabelece-se num campo relacional, num encontro, num entre. Nessa mesma direção, a partir de sua experiência com a aprendizagem da escrita de crianças pequenas, Olsson (2018) afirma que professores, conteúdos, livros, as crianças, estão num campo relacional e num contínuo movimento. "Estão todos relacionados, mas não como entidades fixas encontrando umas às outras; na verdade, é uma relação em si que está em movimento" (OLSSON, 2018, p. 36). 
Deste modo, num movimento de criação e de invenção de uma linguagem escrita, a aprendizagem das primeiras letras de um pequeno escritor não está no movimento de representação de fonemas, de um saber cartilhesco que lhes falta, mas numa afetação e potencialidade corpórea, entendidas não somente como seus corpos físicos, mas tudo e todos que estão a seu redor.

As leituras das personagens e as escritas das crianças são, portanto, acompanhadas de "usos" e "inscrições" do/no corpo no espaço. Assim, leitura e escrita não são apenas operações intelectuais abstratas, elas são usos do corpo, inscrições de um espaço, relação consigo mesmo e com os outros (CAVALLO; CHARTIER, 1997). As personagens-leitoras e as crianças-escritoras estabelecem uma relação com o livro/escrita que antecede a prática efetiva do ato de ler, quando, por exemplo, a constituição do suporte físico para a leitura provoca e desperta sentidos no/a leitor/a (CHARTIER, 2002). Narrados na linguagem escrita das crônicas e na cinematográfica do filme, a materialidade dos objetos de leitura desde o aspecto físico, imagens, impressão e formato constituem elementos que compõem as disposições para a leitura. O suporte material do texto impresso interfere e possibilita "efeitos de sentido" (CHARTIER, 2002, p. 271). Os livros e sua materialidade indicam também modos do que é e como deve ser a leitura literária: no livro e com o livro. Essa discussão revela que no processo de interação com um texto, o/a leitor/a produz sentidos, a partir de sua história e de suas experiências, ou seja, é distinto para cada leitor/a, uma vez que, as experiências, a origem e a história dos leitores/as nunca são iguais.

Esses conceitos afirmam que o processo de ler envolve diversos elementos que antecedem a prática efetiva do ato da leitura. Remete a constituição da materialidade dos objetos da leitura, os materiais específicos, o "uso do corpo", a "inscrição em um espaço", a "relação consigo e com o outro" (CHARTIER, 2002, p.70). As "práticas de leitura" não são apenas uma "operação abstrata de intelecção", mas compreendem as práticas culturais e suas respectivas reorganizações no meio social (CHARTIER, 2002, p.70). Localizadas em uma espécie de consonância com os hábitos culturais de um determinado tempo, os modos de ler referem-se às práticas inscritas em uma rede social e cultural específica. Considerar essa perspectiva significa localizar as modalidades de ler, sejam elas coletivas ou individuais, herdadas ou inovadoras, popular ou letrada, íntimas ou públicas, intensiva ou extensiva, oral ou silenciosa (CHARTIER, 1990).

Desse modo, as práticas de leitura e escrita produzem sentidos e revelam convenções, normas e valores em seus contextos específicos. Os "protocolos de leitura" (CHARTIER, 1996), a interação leitor e texto, e, portanto, as significations plurielles et mobiles ${ }^{6}$ (CHARTIER, 2002), são capazes de inventar, deslocar ou subverter as ideias previamente pensadas pelo escritor para o/a leitor/a. A "corporalidade do leitor" depende das capacidades, dos códigos e das convenções de leitura próprias às diferentes comunidades que constituem, na sincronia ou na diacronia, seus diferentes públicos.

Bloom (2001), crítico literário norte-americano, afirma que não existe um único modo de ler, mas há pretextos que mobilizam a leitura e formas diferenciadas de ler. A leitura é considerada uma prática cultural e não um exercício educativo. Dessa forma, no sentido pragmático, Bloom (2001) assinala que ler provoca prazer (ou desprazer) também em relação a interesses pessoais, num processo de identificação cognitiva, pessoal e estética, que é marcado por expectativas e surpresas em um jogo de sensações e imaginação que são acionados no ato de ler, assim como também o intelecto, que é ativado ao garantir o entendimento e a habilidade de relacionar o que se lê ao que foi vivido ou sentido. O leitor pode desenvolver pensamentos de contemplação sobre a obra como ainda pode contrapor as ideias de um livro. Ao mesmo tempo, Bloom (2001) indica que há possibilidades de o leitor buscar a leitura com a intenção de analisar, refletir, avaliar o que lê e igualmente deve ler plenamente não com a finalidade de acreditar, concordar ou discordar, mas para se identificar com o que é lido.

6 Tradução livre: significações plurais e móveis. 
Partindo das afirmativas de Bloom (2001), podemos dobrá-las mais um pouco na direção de afirmar uma aprendizagem inventiva e o cultivo de um corpo-leitor-escritor, considerando que ler envolve também o desenvolvimento de uma narrativa de si que, aquém e para além da identificação, abrange uma ampliação de si, a composição de novos territórios existenciais, de novos gostos, novas estéticas, novos entendimentos, derivas subjetivas. Imaginar, para nós, não é atividade intelectual inferior à razão, mas é ela mesma uma faculdade de resistência, de recusa ao mundo dado, de invenção de si e do mundo. Aprende-se entre o livro e os olhos, o livro e o dedos, o livro e o corpo, aprende-se no meio, pois um corpo-leitor-escritor é um corpo no mundo, corpo vivo tramado por um encontro fundamental com a leitura e a escrita, atravessado por uma emoção vital ativada pelas forças do mundo que se abrem e se agitam como quando se abre um livro (KASTRUP, 2008a; 2008b; ROLNIK, 2016).

Nessa faceta, o corpo pode ser compreendido como uma usina de memórias em seus acúmulos de histórias que se atualizam e narram o vivido. Essa abordagem permite articular a vertente que admite a memória como construção social e individual e, portanto, constituída em todos os âmbitos (POLLAK, 1992). Além disso, entendemos a cognição, a memória, a aprendizagem como processos inscritos no tempo, o que significa investigá-los do ponto de vista das transformações que neles têm lugar. Nessa direção, além de uma atenção aos estratos históricos, precisamos fazer uma dobra no entendimento que costumamos ter do que seja o tempo, dando uma atenção especial ao presente, que aqui não é entendido com um momento que se segue ao passado e antecede o futuro. A referência não é do tempo mecânico dos relógios, tempo cronológico, linear e sucessivo. Não se trata aqui de um instante matemático, mas do presente real, concreto, vivido, que ocupa necessariamente uma duração. Um presente que encarna a passagem do tempo, a transformação; um presente que possui "uma espessura temporal, que não sucede o passado nem precede o futuro, mas faz coexistirem esses tempos. Do passado, possui a virtualidade; do futuro, a imprevisibilidade" (KASTRUP, 2008a, p.94). Presente que não comparece como um ponto na linha do tempo cronológico, mas como problematização das estruturas históricas.

Com isso, o que queremos salientar é que nossa memória é politemporal, ela também abarca o tempo do devir, promovendo bifurcações nos caminhos traçados pela história e é justamente isso que queremos apontar quando indicamos a memória como atualização do vivido, participando da composição daquilo que estamos a caminho de nos tornar. Assim, nossa memória é composta entre tempos, entre regularidades e instabilidades, no tempo da coexistência entre as formas conservadas, estabilizadas dos estratos históricos e as forças intempestivas extemporâneas que fazem tremer essas mesmas formas, atuando no sentido de desestabilização das condições históricas (KASTRUP, 2008b). Nessa direção que pensamos o corpo como uma usina de memórias.

O eixo central discutido são as disposições do corpo por meio dos sentidos atribuídos à leitura e da produção de um corpo-leitor, de narrativas de si produzidas por meio da leitura a partir das práticas inscritas em uma rede social e cultural, expressas por meio das especificidades e procedimentos nos modos e tipos de leituras. Dessa forma, foram evidenciados aspectos imbricados no ato de ler, que, por sua vez, estão diretamente relacionados aos usos que consideram a forma e os objetos, os suportes e os objetivos da leitura. Gestos da posição do corpo para a leitura como sentado, em pé ou deitado, por exemplo, sugerem a possibilidade da experiência que provoca sensações distintas para cada ocasião, desde a esfera pública à privada. Ao eleger os fatos mais marcantes da história lida ou das experiências de leitura, é possível recorrer à memória que é produzida individual e coletivamente. A relação de como o corpo reage à materialidade do texto influencia a forma como a experiência de leitura é sentida, percebida e compreendida, ou seja, como os sentidos são aguçados. Isso também remete à dimensão subjetiva da leitura (MORAIS, 2014), denominada por tudo o que corresponde aos aspectos de percepção, de sensações, impressões, compreensões e até mesmo produção da memória, produção de si e do mundo por meio do que se leu e como se leu. 
O encontro das personagens-leitoras analisadas e os seus livros pode ser entendido a partir da premissa de que "o leitor é invadido por um texto que o habita, e ao identificar-se com os heróis da narrativa, ele decifra sua própria existência por meio da ficção" (CHARTIER, 2002, p.108). Portanto, as leituras são "intensas" e "intensivas", uma vez que a "sensibilidade" do leitor é comprometida e habita o cotidiano daqueles que se sentem envolvidos na leitura ficcional. De tal modo que a leitura pode envolver emoções que suscitam um "processo afetivo", já que o leitor aciona as capacidades reflexivas em uma espécie de "jogo textual" (JOUVE, 2010, p. 11). Assim, outro aspecto que pode ser aqui considerado é que a literatura (e a leitura literária) pode ser analisada sob várias dimensões, desde as leituras escolares até a sua prática não obrigatória ou não profissional, ou seja, extrapolando os muros da escola.

A literatura pode ser analisada como possibilidades educativas a partir das leituras potencializadas na esfera escolar, mas segundo Mathieu Bégin (2011), raro é localizar pesquisas que se dediquem à literatura, como uma prática de divertimento, de socialização, como um vetor de existencialização, de ampliação de territórios existenciais, de invenção de formas de ser e modos de viver.

No contexto escolar, Silva (1991) propõe que os leitores junto ao professor partilhem e expressem os sentidos mobilizados a que chegaram durante e após a interação com os textos. Desse modo, espera-se a constituição de circuitos de acesso à leitura literária disponibilizando ações que priorizem a acessibilidade do livro à comunidade escolar. Tais referenciais provocam um repensar sobre a sala de aula e aquele que aprende, e desta maneira reinventar e reelaborar os espaços e o modo de relacionar-se com os livros, com os outros e consigo bem como repensar os modos de produzir conhecimento. Para nós, esse repensar também indica a necessidade de problematizar os usos do corpo nas salas de aula, os usos do livro, da literatura, e os sentidos de cognição (restrita a processamento de informação e representação de um mundo dado) e de aprendizagem (restrita a representar um mundo dado). Em síntese, referimo-nos a propostas de experiências sensoriais que mobilizam os sentidos e, assim, concebem novos modos de experimentar o encontro da criança-leitora e o livro no ambiente escolar.

"A literatura pode ser um espaço bonito do reencontro, da conversa, do deslanchar para outras coisas, para outras confidências" (QUEIRÓS, 2011, p.13). Experiências fundamentadas em princípios que valorizem práticas de escuta das crianças, o pensamento fluido e a imaginação livre podem nortear redes de afectos na escola. Partindo dessa premissa, admite-se que a construção de uma criança leitora não se resume apenas às técnicas e procedimentos de leitura, mas, na intrínseca necessidade de envolvê-la nas diferentes narrativas literárias e assim, assuma processos de conhecimento-criação de si, do outro, e do mundo.

\section{Para que continuemos a ler!}

Os estudos em torno da infância e a paixão pela leitura literária é o que une as/o autoras/or desta escrita. No entanto, ainda com Kastrup (2008b) precisamos fazer uma ressalva: não se trata de uma paixão romântica. Nosso acoplamento cognitivo com textos literários e nossa aposta em uma leitura e escrita infante como capazes de produzir derivas subjetivas não significa nostalgia, apego a um passado que não voltará, posto que não há nem desejamos retorno possível, "é inconcebível retornar a formas anteriores de conhecer e viver" (KASTRUP, 2008b, p. 241). Ainda com a imagem de Stella saindo da livraria, correndo alegre com um livro nas mãos, o novo não coincide com modismos, não tem a ver com os best-sellers literários ou com um cinema de entretenimento que lota bilheterias. O novo que espreitamos tem a ver com o que move a criação de modos de pensar, de formas de ver e de dizer. 
Assim, quando falamos da infância da escrita e da leitura, fazemos um convite à força dos interstícios e intervalos escolares, ali, onde aquém e além dos conteúdos a serem instruídos, pessoas estão reunidas ao redor de um livro abrindo as palavras, abrindo o mundo, abrindo-se. Ali, onde aprender não tem a ver com repetição mecânica, tédio e decoreba, aprender tem a ver com uma arte, com a emoção de abrir-se à experiência e ali fabular mundos: "o que é preciso é pegar alguém que esteja 'fabulando', em 'flagrante delito de fabular'” (DELEUZE, 1992b, p. 157) outros modos de ver e dizer, balbuciando uma língua para a educação escolar.

Entre o livro e o corpo, uma maquinação. Aprende-se uma arte de viver, caminhos de vida. Assim, além da desconstrução da imagem da criança como tábula rasa, consumidora e reprodutora de conhecimento e da cultura, como mundos dados, que possamos, por meio do tateio desses caminhos de vida, inventar outras imagens e outras línguas de criança, do professorar, da função do livro como ferramenta pedagógica. Que o currículo se abra a perguntas infantilantes, que a prática pedagógica vislumbre processos de aprendizagem em curso, aberturas de si e de mundos, composições de paisagens. Continuemos, a ler e a escrever, caminhos.

\section{Referências}

ABRAMOWICZ, Anete. Educação infantil: implementar o exercício da infância. In: ABRAMOWICZ, Anete; TEBET, Gabriela. Infância e pós-estruturalismo. São Paulo: Porto de ideias, 2017, p. 29-80

AGAMBEN, Giorgio. Infância e história: destruição da experiência e origem da história. Belo Horizonte: Editora UFMG, 2005, 188p.

ALVIM, Davis Moreira; MAÇÃO, Davis Moreira. Uma filosofia das crianças: forças, meios e invenções. In: RODRIGUES, Alexsandro (org.). Crianças em dissidências: narrativas desobedientes da infância. Salvador: Editora Devires, 2018, p. 71-86.

BARROS, Manoel. O livro das ignorãças. Rio de Janeiro: Alfaguara, 2016, 120p.

BIESTA, Gert. Para além da aprendizagem: educação democrática para um futuro humano. Belo Horizonte: Autêntica, 2017, 208p.

BÉGIN, Mathieu. Le forum de discussion sur Internet comme lieu d'étude de la réception des productions littéraires jeunesse: le cas de la série Pavel 1. Communication, Lettres Et Sciences du Langage, v. 5, n 1. ago. 2011.

BLOOM, Harold. Como e por que ler. Rio de Janeiro: Objetiva, 2001, 276p.

CAMPESATO, Maria Alice Gouvêa; RODRIGUES, Elisandro; SCHULER, Betina. Escrita, leitura e o tempo da educação. In: RODRIGUES, Allan; BERLE, Simone; KOHAN, Walter (orgs.). Filosofia e educação em errância: inventar a escola, infâncias do pensar. Rio de Janeiro: NEFI, 2018, p. 303-315.

CAVALLO, Guglielmo; CHARTIER, Roger (Coords.). Histoire de la lecture dans le monde occidental. Paris: Éditions Seuil, 1997, 592p.

CHARTIER, Roger. A história cultural: entre práticas e representações. Rio de Janeiro: Bertrand Brasil, 1990, $244 p$.

CHARTIER, Roger. (Org.). Práticas de leitura. São Paulo: Estação Liberdade, 1996, 268p

CHARTIER, Roger. À beira da falésia: a história entre incertezas e quietudes. Porto Alegre: Editora da UFRGS, $2002,277 p$.

DELEUZE, Gilles. Post-scriptum: sobre as sociedades de controle. In: Conversações. São Paulo: Editora 34, 1992a, p. 223-230. 
DELEUZE, Gilles. Três questões sobre seis vezes dois. In: Conversações. São Paulo: Editora 34, 1992b, p. 53-63.

DELEUZE, Gilles, GUATTARI, Felix. O que é filosofia?. Rio de Janeiro: Editora 34, 1992, 288p.

DIDI-HUBERMAN, Georges. Que emoção! Que emoção?. São Paulo: Editora 34, 2016, 72p.

DUSSEL, Inés. Sobre a precariedade da escola. In: LARROSA, Jorge (org.). Elogio da escola. Belo Horizonte: Autêntica, 2017, p. 87-111.

GADELHA, Sylvio. Educação, políticas de subjetivação e sociedade de controle. In: MARCONDES, Adriana; FERNANDES, Ângela; ROCHA, Marisa (org.). Novos possíveis no encontro da Psicologia com a Educação. São Paulo: Casa do Psicólogo, 2013, p. 15-36.

JOUVE, Vincent. La Lecture. Paris: Hachette Collection - Contours Littéraires, 2008, 106p.

JOUVE, Vincent. Pourquoi étudier la littérature? Paris: Armand Colin, 2010, 224p.

KASTRUP, Virgínia. A cognição contemporânea e a aprendizagem inventiva. In: KASTRUP, Virgínia; TEDESCO, Silvia; PASSOS, Eduardo. Políticas da cognição. Porto Alegre: Sulinas, 2008a, p. 93-112.

KASTRUP, Virgínia. Sobre livros e leitura: algumas questões da aprendizagem e oficinas literárias. In: KASTRUP, Virgínia; TEDESCO, Silvia; PASSOS, Eduardo. Políticas da cognição. Porto Alegre: Sulinas, 2008b, p. $241-266$.

KOHAN, Walter. A infância da educação: o conceito devir-criança. In: Infância, estrangeiridade e ignorância. Belo Horizonte: Autêntica, 2007, p. 85-98.

LARROSA, Jorge. Literatura, experiência e formação. In: COSTA, Marisa Vorraber. Caminhos investigativos I: novos olhares na pesquisa em educação. Belo Horizonte: DP\&A, 2007, p. 129-156.

Jorge. Notas sobre a experiência e o saber da experiência. In: Tremores: escritos sobre experiência. Belo Horizonte: Autêntica, 2014a, p. 15-34.

Jorge. Ferido de realidade e em busca de realidade. Notas sobre as linguagens da experiência. In: Tremores: escritos sobre experiência. Belo Horizonte: Autêntica, 2014b, p. 73-122.

Jorge. Abecedário com Jorge Larrosa Bondía. Depoimento. [nov 2016]. (1h10min). Rio de Janeiro: CINEAD LECAV Disponível em: https://www.youtube.com/watch?v=5FtY1psRoS4 . Acesso em 24 maio 2020. $523 p$. Jorge. Esperando não se sabe o quê: sobre o ofício de professor. Belo Horizonte: Autêntica, 2018,

LAVAL, Christian. A escola não é uma empresa: o neoliberalismo em ataque ao ensino público. São Paulo: Boitempo, 2019, 288p.

LISPECTOR, Clarice. Felicidade clandestina. In: Todos os contos. Rio de Janeiro: Rocco, 2016, p. 393-396.

MORAIS, Roselusia Teresa Pereira de. Modos de ler o impresso, modos de escrever na internet: escritas de leitores e leitoras do escritor Erico Verissimo. 221 f. Tese (Doutorado em Educação) - Programa de PósGraduação em Educação, Faculdade de Educação, Universidade Federal de Pelotas, Pelotas, 2014.

MASSCHELEIN, Jan; SIMONS, Maarten. Em defesa da escola: uma questão pública. Belo Horizonte: Autêntica, 2013, 174p.

MILANEZ, Fernanda. Livros e panos. In: VENAS, Raíza; RIBES, Rita. Infância crônica. Rio de Janeiro: Nau, 2019, p. 81-82.

OLSSON, Liselott. Movimento e experimentação na aprendizagem de crianças pequenas. In: ABRAMOWICZ, Anete; TEBET, Gabriela. Infância e pós-estruturalismo. São Paulo: Porto de ideias, 2017, p. 29-80.

POLLAK, Michael. Memória e Identidade Social. In: Estudos Históricos, Rio de Janeiro, v. 5, n. 10, 1992. Disponível em: <http:// www.ebah.com.br/content/ABAAAA28kAC/memoria-identidade-social>. Acesso em: 04 jul. 2013. 
QUEIRÓS. Bartolomeu Campos de. A literatura é esse espaço onde o que sonhamos encontra o diálogo. Curitiba, Paiol Literário, Jornal Rascunho. 07 jun. 2011. Entrevista a Rogério Pereira. Disponível em: <http://rascunho.com. br/bartolomeu-campos-de-queiros/> Data de acesso: 17 out. 2018, p.1-15.

ROLNIK, Suely. A hora da micropolítica. Coleção Pandemia, vol. 1. São Paulo: n-1 edições, 2016, 31p.

SIBILIA, Paula. Redes ou paredes: a escola em tempos de dispersão. Rio de Janeiro: Contraponto, 2012, 224p.

VASCONCELOS, Michele de Freitas Farias de; PRATES, Rui Benevides; MELO, Marcos Ribeiro de. Infância, cinema, lirismo: a poética do sonho de Wadjda. Momentos: diálogos em educação, v. 28, n.3, p. 26-46, set./ dez. 2019. Disponível em: https://periodicos.furg.br/momento/article/view/8393/6320. Acesso em 25 maio 2020.

VASCONCELOS, Michele de Freitas Farias de; MELO, Marcos Ribeiro de; SOUZA NETO, Edson Augusto de. Etnocartografar com olhos rebeldes: infantilando imagens com "A culpa é do fidel". Interdisciplinar, v. 29, jan.jun., p. 207-223, 2018. Disponível em: https://seer.ufs.br/index.php/interdisciplinar/article/view/9633. Acesso em 25 de maio de 2020.

STELLA. Direção: Sylvie Verheyde. [S.I.]: Lume Filmes, 2008, 1 DVD (1h43min).

WUNDER, Alik. Das imagens que movem o pensar. In: SCARELI, Giovana; FERNANDES, Priscila Correia (org.). O que te move a pesquisar?: ensaios e experimentações com cinema, educação e cartografias. Porto Alegre: Sulina, 2016, p. 12-31.

Recebido em: 15/01/2020

Aceito em: 30/04/2020 